\section{Prognosis in severe shock}

Severe shock is an infrequent but life-threatening complication of various illnesses. Patients who develop shock are usually transferred promptly to an intensive or coronary care unit, where treatment may be time consuming, complex, and often unrewarding.

If we could identify factors that accurately predicted the outcome in severe shock new treatment methods would be easier to evaluate and more efficient use might be made of scarce and costly resources. Nevertheless, no single prognostic factor has proved to be conclusively reliable, though combinations of factors ${ }^{1-3}$ and repeat measurements ${ }^{4}$ may increase the accuracy of prediction in groups of patients.

Among the problems that have frustrated attempts to develop prognostic indices are the increasing success of acute cardiorespiratory resuscitation and the multiple causes of shock. Many patients appear to make an adequate initial recovery only to die as a consequence of some late effect of shock or of the underlying disease or a combination of both. ${ }^{6}$ Outcome relates more closely to the duration of shock (which is often difficult to quantify) than to its severity. The onset of cardiac, respiratory, ${ }^{7}$ or renal failure, persistent jaundice, ${ }^{8}$ and a clouding of consciousness ${ }^{9}$ all augur ill for long-term survival (particularly in the elderly). Despite these observations multiple organ failure by no means always portends death. ${ }^{10}$

Changes in the standard haemodynamic variables are of little value, ${ }^{11}$ though more refined measurements do improve the accuracy of prediction. Patients with myocardial infarction $^{12} 13$ may be classified into four groups on the basis of the results of measuring cardiac output and pulmonary capillary pressure, with mortality varying from $1 \%$ in the least affected to over $60 \%$ in the most severely affected group. In hypovolaemic and septic shock low cardiac output, ${ }^{14}$ persistently raised pulmonary vascular resistance, ${ }^{15}$ and low peripheral skin temperature $^{16}$ have some association with outcome, but the reported degree of correlation varies widely among centres. In hypovolaemic shock the ability to increase standardised stroke work (a value derived from left ventricular stroke work and pulmonary capillary wedge pressure) in response to intravascular fluid infusion may forecast a successful result, ${ }^{17}$ and in septic shock a normal blood flow velocity and plasma volume are favourable indicators. ${ }^{14} \mathrm{~A}$ more generally applicable test based on the changes produced by dopamine infusion on toe temperature ${ }^{11}$ seems to allow early separation of survivors and non-survivors. Respiratory variables are not particularly helpful, though in one group of severely shocked patients the degree of intrapulmonary shunt at the time of admission was of prognostic value. ${ }^{18}$

Both the systemic and pulmonary vascular changes described above may be caused by the release into the circulation of vasoactive substances including the catecholamines, histamine, serotonin, and prostaglandins; so measurement of the concentrations of these agents in the blood during the acute phase of shock might be expected to relate to outcome. ${ }^{1920}$ Coincidental intravascular aggregation and coagulation may occur in any form of shock, though these changes are seen most commonly in septic shock. In one recent study a raised partial thromboplastin time was a poor prognostic feature $^{18}$; persistent thrombocytopenia and endotoxaemia ${ }^{21}$ as well as complement activation ${ }^{22}$ are all more appreciable in fatal septic shock.

Metabolic determinants of outcome in severe shock have recently attracted increasing attention. The relation between poor perfusion and acidosis has been recognised for many years, but by itself a low arterial $\mathrm{pH}$ is a poor guide to prognosis. ${ }^{115}$ Arterial blood lactate concentrations have been advanced as a better indicator of tissue hypoperfusion, anaerobic glycolysis, and cumulative oxygen debt, ${ }^{23}$ but the interpretation of raised values is not as simple as once thought. Hepatic dysfunction may result in high blood concentrations during a minor episode of shock, and, though appreciably raised concentrations may occur in cardiogenic and hypovolaemic shock, those in septic shock are lower and do not relate well to outcome. ${ }^{24}$ It is the changes in lactate in response to acute resuscitation that seem to provide a better indication of prognosis, with a fall during the first few hours suggesting a favourable outcome. ${ }^{525}$ The glucose to lactate ratio is reported to be of value in septic shock. ${ }^{26}$

An oxygen consumption below $120 \mathrm{ml} / \mathrm{min} / \mathrm{m}^{2}$ in the early phase of shock is commonly associated with a failure to survive, and in septic shock a similar outcome occurs when oxygen consumption exceeds twice normal. ${ }^{27}$ In practice, the measures may be of little help since there will be no baseline figures for oxygen consumption before the patient went into shock and continuous, accurate measurements present technical difficulties. Mixed venous oxygen tension (or saturation) is a good indicator of the overall adequacy of tissue perfusion and oxygenation, and techniques are available for continuous display by the bedside ${ }^{28}$; a value below $50 \%$ is associated with a low cardiac output and a poor prognosis. ${ }^{29}$

The metabolic derangements of severe shock may raise serum enzyme activities, and this may be of prognostic value, ${ }^{18}$ but the changes are often difficult to interpret in patients after surgical or accidental injury. In shock associated with trauma the injury severity score ${ }^{30}$ relates better to outcome than, for example, estimated blood loss; intensive care may merely prolong time to death. ${ }^{31}$

Clearly, then, prognostic indices are least reliable in the early stages of shock, when their value would be greatest. That being the case, every shocked patient should have the benefit of immediate resuscitation. Long-term survival depends on many factors, including age, duration of shock, organ failure, and underlying disease. Efficient use of intensive care units depends on accurate and repeated clinical assessments in the later phases of shock.

I MCA LEDINGHAM Professor of intensive care B N CowaN Anaesthetic research fellow H J G BURNS Lecturer in surgery

Western Infirmary,

Glasgow G11 6NT

1 Shubin H, Weil MH, Afifi AA, Portigal L, Chang P. Selection of hemodynamic, respiratory and metabolic variables for evaluation of patients in shock. Crit Care Med 1974 ;2:326-36.

2 Pierchala C, Shoemaker WC, Chang P. A comparison of some methods for early classification of survivors and nonsurvivors of postoperative shock. Comput Biol Med 1978;8:279-92.

${ }^{3}$ Civetta JM. Selection of patients for intensive care. In: Ledingham IMcA, ed. Recent advances in intensive therapy. Edinburgh: Churchill Livingstone, $1977: 9-18$.

4 Chang PC, Weil MH, Portigal LD, Shoemaker WC. Prognostic indices and predictors for patients in circulatory shock. In: Ledingham IMcA, ed. Recent advances in intensive therapy. Edinburgh: Churchill Livingstone, 1977:19-31.

5 Vincent JL, Dufaye P, Berre J, Leeman J, Degante JF, Kahn RJ. Lactate metabolism during circulatory shock. Crit Care Med 1981;9:234.

6 Ledingham IMcA, McArdle CS. Prospective study of the treatment of septic shock. Lancet 1978 ; :1194-7.

7 Kaplan RL, Sahn SA, Petty TL. Incidence and outcome of the respiratory distress syndrome in Gram-negative sepsis. Arch Intern Med 1979;139: 867-9.

8 Royle GT, Kettlewell MGW. Liver function tests in surgical infection and malnutrition. Ann Surg 1980;192:192-4. 
${ }^{9}$ Golden PF, Jane JA. Experimental study of irreversible shock and the brain. I Neurosurg 1973;39:434-41.

${ }^{10}$ Routh GS, Mone JG, Briggs JD, Ledingham IMcA. Survival from acute renal failure with and without multiple organ dysfunction. Postgrad Med $\mathcal{f} 1980 ; 56: 244-7$.

${ }^{11}$ Ruiz CE, Weil $\mathrm{MH}$, Carlson RW. Treatment of circulatory shock with dopamine. Studies on survival. F $A M A 1979 ; 242: 165-8$.

12 Forrester JS, Diamond G, Chaterjee K, Swan HJC. Medical therapy of acute myocardial infarction by application of hemodynamic subsets. N Engl f Med 1976;295:1356-62.

${ }^{13}$ Forrester JS, Waters DD. Hospital treatment of congestive heart failure. Management according to hemodynamic profile. Am $\mathcal{F}$ Med 1978;65: 173-80.

14 Nishijima $\mathrm{H}$, Weil $\mathrm{MH}$, Shubin $\mathrm{H}$, Cavanilles J. Hemodynamic and metabolic studies on shock associated with Gram negative bacteremia. Medicine (Baltimore) 1973;52:287-94.

${ }^{15}$ Shoemaker WC, Elwyn D, Levin H, Rosen AL. Early prediction of death and survival in postoperative patients with circulatory shock by nonparametric analysis of cardiorespiratory variables. Crit Care Med 1974; 2:317-25.

16 Joly HR, Weil MH. Temperature of the great toe as an indication of the severity of shock. Circulation $1969 ; 39: 131-8$.

${ }^{17}$ Czer LSC, Shoemaker WC. Myocardial performance in critically ill patients: response to whole blood transfusion as a prognostic measure. Crit Care Med 1980;8:710-5.

${ }^{18}$ Hardaway RM. Prediction of survival or death of patients in a state of severe shock. Surg Gynecol Obstet 1981;152:200-6.

19 Griffiths J. The sequential assay of plasma catecholamines and whole blood histamine in early septic shock. In: Ledingham IMcA, McAllister T, eds. Conference on shock. London: Henry Kimpton Ltd, 1972:76-83.

20 Benedict CR, Grahame-Smith DG. Plasma noradrenaline and adrenaline concentrations and dopamine-B-hydroxylase activity in patients with shock due to septicaemia, trauma and haemorrhage. $Q \mathcal{J} \mathrm{Med} 1978 ; 47$ : 1-20.

21 Ledingham IMcA, McArdle CS, Macdonald RC. Septic shock. In: Taylor $\mathrm{S}$, ed. Recent advances in surgery. Edinburgh: Churchill Livingstone, 1980:161-99.

${ }^{22}$ Whaley K, Khong TY, McCartney AC, Ledingham IMcA. Complement activation and its control in Gram-negative endotoxic shock. $\mathcal{F}$ Clin Lab Immunol $1979 ; 2: 117-24$.

${ }^{23}$ Broder G, Weil MH. Excess lactate: an index of reversibility of shock in human patients. Science $1964 ; 143: 1457-9$.

${ }^{21}$ Perret $\mathrm{C}$, Enrico JF. Lactate in acute circulatory failure. In : Bossart $\mathrm{H}$, Perret C, eds. Lactate in acute conditions. Basle: Karger, 1979:69-82.

${ }^{25}$ Burns HJG, Cowan BN, Ledingham IMcA. Metabolic acidosis in the critically ill. In : Porter R, Alberti KGMM, eds. Metabolic acidosis. CIBA symposium 87 . (In press.)

${ }^{26}$ Schumer W. Septic shock. $\mathcal{F} A M A$ 1979;242:1906-7.

27 Shoemaker WC, Montgomery ES, Kaplan E, Elwyn DH. Physiologic patterns in surviving and nonsurviving shock patients. Use of sequential cardiorespiratory variables in defining criteria for therapeutic goals and early warning of death. Arch Surg 1973;106:630-6.

${ }^{28}$ Polanyi ML. Fiberoptics in cardiac catheterisation. I: Theoretical considerations. In: Bloomfield DA, ed. Dye curves: the theory and practice of indicator dilution. Baltimore: University Park Press, 1974:267-83.

${ }^{29}$ Kasnitz P, Druger GL, Yorra F, Simmons DH. Mixed venous oxygen tension and hyperlactaemia. Survival in severe cardiopulmonary disease. $\mathcal{F} A M A$ 1976;236:570-4

${ }^{30}$ Baker SP, C'Neill B, Haddow W, Long WB. The injury severity score: a method for describing patients with multiple injuries and evaluating emergency care. $\mathcal{F}$ Trauma 1974 ;14:187-96.

${ }^{31}$ Bull JP. The injury severity score of road traffic casualties in relation to mortality, time of death, hospital treatment time and disability. Accident, Analysis and Prevention 1975;7:249-55.

\section{The perils of abstention?}

The notion that a little of what you fancy does you good appears to receive support from a recent study by Klatsky et al ${ }^{1}$ from the Kaiser-Permanente programme. In a large 10-year prospective investigation they found that mortality varied according to the drinking habits of the individuals on entry to the study. Four groups with different levels of consumption were drawn from people undergoing multiphasic health examinations, matched according to the age, sex, and race of the highest-drinking category. The lowest mortality was found for those consuming an average of up to two drinks a day. With this rate as unity abstainers had a relative risk of 1.5 , those drinking three to five drinks daily also had a risk of $1 \cdot 5$, and $\stackrel{\text { mo }}{3}$ heavier drinkers had a risk of 2 . Plotting mortality risk against consumption thus produced a U-shaped curve. Independent $c$ confirmation of this pattern is provided by a recent London- $\widehat{\widehat{\Omega}}$ based study by Marmot et $a l,{ }^{2}$ which, though smaller in scale $\overline{\overline{5}}$ and using a different analytic procedure, also found that $\mathbb{\Phi}_{\mathbb{D}}$ moderate drinkers had a lower 10-year mortality than either $\infty$ non-drinkers or heavier drinkers. Other studies, ${ }^{3}{ }^{4}$ too, have $ᄋ$ reported a U-shaped relation. Nevertheless, if it were possible to recruit adequate samples of drinkers at higher levels of $\stackrel{5}{+}$ consumption the results would probably show not a linear but an exponential increase in mortality with increasing intake, $\frac{\bar{\sigma}}{\bar{\omega}}$ much as has been shown for cirrhosis of the liver": the " $U$ " might be a "J."

Whatever the details, it seems paradoxical that anyone's life might be shortened by the absence of a toxic substance such $\vec{\circ}$ as ethanol. The picture changes, however, when cause-specific $\overrightarrow{\vec{\omega}}$ mortality rates are considered. It then emerges from the studies $\stackrel{\circ}{\circ}$ of both Klatsky et $a l^{1}$ and Marmot et $a l^{2}$ that the excess mortality among abstainers is largely due to an increase of cardio- iv vascular deaths, the frequency of which steadily declines with $\stackrel{\infty}{\oplus}$ increasing daily consumption within the range of levels $\underset{\omega}{ }$ represented. This trend has been much explored by other $\vec{P}$ workers, with conflicting results. Conversely, other causes of mortality-among which cancer and violent deaths figure $\omega$ prominently-increase with increasing daily intake, and about this relation there is general consensus in published work.

Several points need clarification before the Kaiser- $\mathbb{D}$ Permanente findings ${ }^{1}$ can be properly evaluated. Firstly, the categorisation of drinking habits is exceedingly crude with no attempt at verification, and there is no evidence that persons $\overrightarrow{\vec{\theta}}$ remained within their initial drinking category over the $10 \stackrel{\infty}{\infty}$ years of follow-up. Given that people tend to drink less as they age, ${ }^{6} 7$ the stability of drinking practices over such a period could hardly be expected. These considerations, however, would tend to blur rather than accentuate the differences among the initial subgroups. A second major query concerns $\stackrel{\odot}{\perp}$ smoking, which is relatively heaviest among drinkers. Both Klatsky et $a l^{1}$ and Marmot et $a l^{2}$ went to some lengths to $\frac{\circ}{3}$ analyse their data carefully for smoking. The Americans found the U-shaped alcohol mortality curve present at each smoking level, except, oddly enough, among those who had never smoked. Marmot et al, using a multivariate technique, again found the association between alcohol mortality to be $\frac{0}{0}$ largely independent of smoking. A third consideration is that those individuals already suffering from alcohol-related damage or suffering from any other illness at entry to the study may have given up drinking as a consequence. Klatsky et al had information at least about past heavy drinking and $N$ reanalysed their data with attention to those with and without $\rightarrow$ such a history; for both groups the same curve was obtained. In a supplementary analysis ${ }^{8}$ the London group distinguished $N$ those taking any medications or with symptoms of diabetes, $\mathbb{\omega}$ cardiovascular, or chronic respiratory disease and contrasted $\mathcal{F}$ them with the supposedly healthy remainder. Similar findings emerged for both samples, though interestingly the highest $\Phi_{\infty}$ mortality of all was found in the so-called "unhealthy abstainers."

So far, then, the claim for an association between mortality and abstention holds up, but three further considerations remain. The first of these is age. Klatsky et al ${ }^{1}$ reported on a cohort whose mean age at entry was 44 , while no one below 40 was admitted to the study by Marmot et al..$^{2}$ Yet (for institutionalised alcoholics) the maximum effect of alcohol on mortality is in the first and not the second half of life. Thus in 